\title{
Carnitine Deficiency and Improvement of Muscle Cramp by Administration of Carnitine in Patients with Liver Cirrhosis
}

\author{
Naoki Hotta \\ Department of Internal Medicine, Division of Hepatology, Masuko Memorial Hospital, Aichi, Japan \\ Email: hotta4166@yahoo.co.jp
}

Received 25 March 2014; revised 30 April 2014; accepted 8 May 2014

Copyright (C) 2014 by author and Scientific Research Publishing Inc.

This work is licensed under the Creative Commons Attribution International License (CC BY). http://creativecommons.org/licenses/by/4.0/

(c) (i) Open Access

\begin{abstract}
Aim: We measured carnitine levels in patients with carnitine including dialysis patients, and examined whether administration of L-carnitine improved muscle symptoms. Methods: We measured carnitine levels in 27 patients with liver cirrhosis who were receiving treatment in our hospital, and administered L-carnitine $(600 \mathrm{mg}-1800 \mathrm{mg})$ to patients having muscle cramps for approximately one month and examined the presence/absence of the symptom. We measured carnitine concentration before and after dialysis, before dialysis after the administration to eight dialysis patients, before and after the administration to 19 nondialytic patients. Results: The total carnitine levels before the dialysis of dialysis patients were an average of $42.2 \mu \mathrm{mol} / \mathrm{L}$ and fell to 17.7 $\mu \mathrm{mol} / \mathrm{L}$ after more dialysis, but it was increased to $155 \mu \mathrm{mol} / \mathrm{L}$ after the administration of L-carnitine. In the nondialytic patients, the total carnitine levels were significantly increased from $\mathbf{7 1 . 7}$ $\mu \mathrm{mol} / \mathrm{L}$ to $101.7 \mu \mathrm{mol} / \mathrm{L}$ after the administration of $\mathrm{L}$-carnitine $(P=0.038)$. For symptomatic patients, significant improvement of muscle clamps was observed in the L-carnitine administrated group when compared with the non-administrated group $(P=\mathbf{0 . 0 0 0 2})$. Conclusions: Total carnitine levels were low even before dialysis in the dialysis patients with liver cirrhosis in particular and they further decreased after the dialysis. Administration of L-carnitine increased the total carnitine levels and improved the symptom. Based on these results, we conclude that L-carnitine is useful for carnitine deficiency in patients with liver cirrhosis.
\end{abstract}

\section{Keywords}

Carnitine, Liver Cirrhosis, Dialysis Patient

\section{Introduction}

In recent years, we occasionally come across some reports that carnitine is useful for improving blood ammonia 
and cognitive function in hepatic cirrhosis patients with latent hepatic encephalopathy [1]-[3]. Recently, levocarnitine chloride (L-Cartin ${ }^{\circledR}$ tablets $100 \mathrm{mg}, 300 \mathrm{mg}$ : Otsuka Pharmaceutical Co., Ltd., hereinafter referred to as LC) has also become available in Japan as a pharmaceutical agent for patients suspected of having carnitine deficiency. We measured serum carnitine concentrations in hepatic cirrhosis patients including dialysis patients and examined whether their cramps improved or not. Muscle spasms and hypotension during dialysis, atrophy of skeletal muscles and decrease in exercise capacity, anemia, and reduced cardiac function associated with decreased carnitine levels in dialysis patients have been reported [4]-[6]. Whereas a majority of the reports on the utility of carnitine have used supplements, we used LC for this investigation.

\section{Methods}

\subsection{Patients}

This was a randomized, double-blind, placebo-controlled study.

The serum carnitine concentrations in 27 patients with hepatic cirrhosis who are outpatients at our hospital were measured by using the enzyme cycling method (total carnitine reference value $45.0-91.0 \mu \mathrm{mol} / \mathrm{L}$, free carnitine reference value 36 - $74 \mu \mathrm{mol} / \mathrm{L}$, acylcarnitines reference value $6-23 \mu \mathrm{mol} / \mathrm{L})$. LC (600 - $1800 \mathrm{mg}$ ) was administered to patients with cramps for 1 month, and the presence or absence of the symptom was examined. Serum carnitine concentrations were measured before and after dialysis and after LC administration in 8 dialysis patients, and before and after administration in 19 non-dialysis patients. In 17 patients with the symptom, the serum carnitine concentrations following administration were measured 1 month later. The study was reviewed and approved by the ethics committee established in the Masuko Memorial Hospital. The patients were given explanation on the study, for which written consents were obtained.

The 27 patients consisted of 8 dialysis and 19 non-dialysis patients, with no differences in the background factors (age, sex, cause, Child-Pugh grade, complication by liver cancer, implementation of dialysis, and with or without administration of branched-chain amino acids, hereinafter referred to as BCAAs, formulation) between the two groups. A significant difference was noted in serum total carnitine concentrations (Table 1). A significant difference was observed in serum total carnitine concentration between the dialysis patients prior to dialysis and the non-dialysis patients $(42.2 \pm 19.5 \mu \mathrm{mol} / \mathrm{L}$ vs. $70.5 \pm 20.7 \mu \mathrm{mol} / \mathrm{L}, P=0.004)$ (Figure 1$)$. In the present study, cramps, one of the symptoms experienced by patients with hepatic cirrhosis, developed in 67\% (18 of 27 patients) of the patients, consisting of 50\% (4 of 8 patients) of the dialysis patients and 74\% (14 of 19 patients) of the non-dialysis patients (Table 2(a)). The administration of LC caused the cramps to disappear in 92\% (12 of

Table 1. The 27 patients consisted of 8 dialysis and 19 non-dialysis patients, with no differences in the background factors (age, sex, cause, Child-Pugh grade, complication by liver cancer, implementation of dialysis, and with or without administration of branched-chain amino acids, hereinafter referred to as BCAAs, formulation) between the two groups. A significant difference was noted in serum total carnitine concentrations.

\begin{tabular}{|c|c|c|c|}
\hline \multicolumn{4}{|c|}{ Baseline participant characteristics } \\
\hline & Hemodialysis $\mathrm{n}=8$ & Non-hemodialysis $\mathrm{n}=19$ & $P$ value \\
\hline Age mean \pm S.D. & $62 \pm 11$ & $66 \pm 9$ & $0.32^{*}$ \\
\hline Sex male/female & $5 / 3$ & $12 / 7$ & $1.00^{* *}$ \\
\hline Etiology (Alco/HBVHCV//nonBnonC/other) & 0/0/7/0/1 & 6/2/10/1/2 & $0.10^{* *}$ \\
\hline Child-pugh grade (A/B/C) & $4 / 4 / 0$ & $10 / 5 / 4$ & $0.38^{* *}$ \\
\hline Child-pugh score mean \pm S.D. & $6.5 \pm 1.2$ & $7.1 \pm 2.7$ & $0.43^{* *}$ \\
\hline HCC complication (\%) & $7(88)$ & $12(63)$ & $0.36^{* *}$ \\
\hline Total-carnitine mean \pm S.D. $\mu \mathrm{mol} / \mathrm{L}$ & $42.2 \pm 19.5$ & $70.5 \pm 20.7$ & $0.004^{*}$ \\
\hline BCAA treatment (\%) & $4(50)$ & $11(58)$ & $1.00^{* *}$ \\
\hline L-carnitine treatment (\%) & $5(63)$ & $11(63)$ & $1.00^{* *}$ \\
\hline Cr mean \pm S.D. mg/dL & $8.9 \pm 2.8$ & $0.9 \pm 0.4$ & $<0.0001^{*}$ \\
\hline
\end{tabular}

*Student's t test; ${ }^{* *}$ Fisher's exact test. 


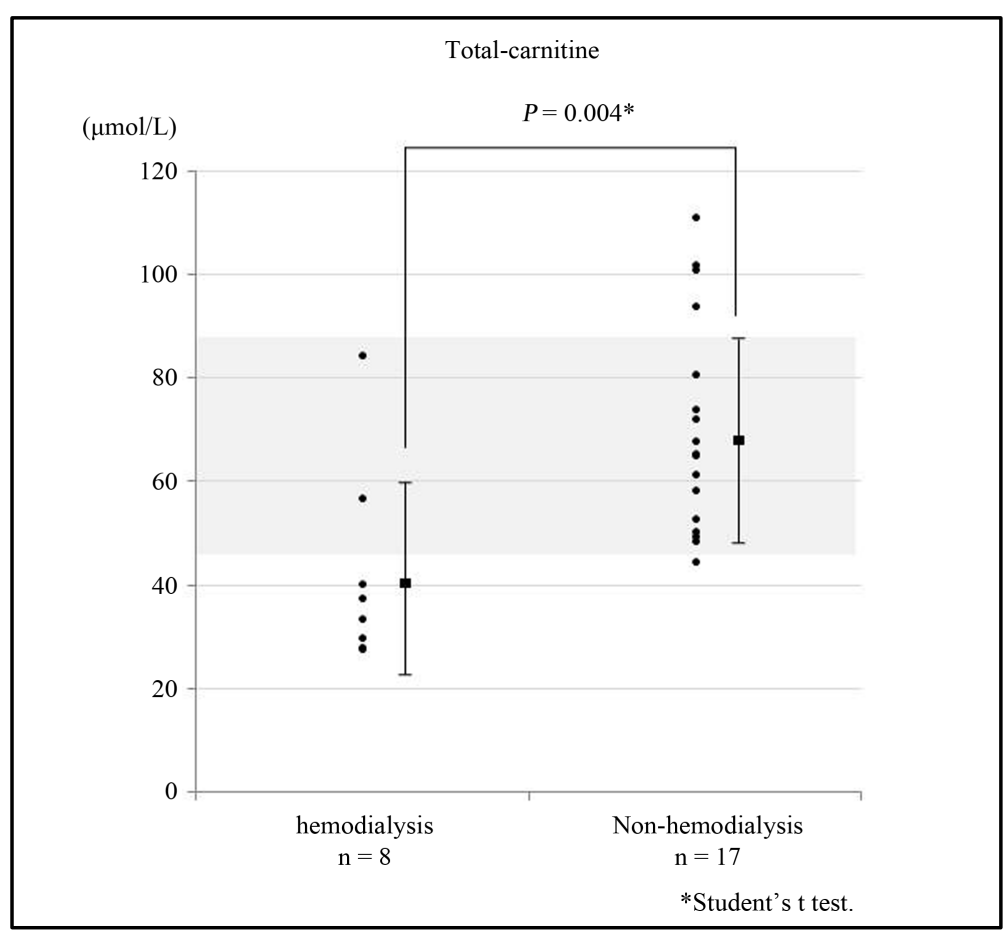

Figure 1. A significant difference was observed in serum total carnitine concentration between the dialysis patients prior to dialysis and the non-dialysis patients $(42.2 \pm 19.5 \mu \mathrm{mol} / \mathrm{L}$ vs. $70.5 \pm 20.7 \mu \mathrm{mol} / \mathrm{L}, P=0.004)$.

13 patients) of the patients, while the symptom did not disappear in the absence of LC administration, showing a significant difference between the two groups $(P=0.0002)$ (Table 2(b)).

\subsection{Statistical Analysis}

With respect to test methods, the paired t-test and Student's t-test were used for paired continuous variable data and unpaired continuous variable data, respectively, and the chi-square test or the Fisher's exact test was used for categorical variable data. All tests were two-sided, and difference levels of $p<0.05$ were considered statistically significant.

\section{Results}

\subsection{Dialysis Patients}

The total carnitine concentration of 6 dialysis patients whose serum carnitine concentrations were measured was a subnormal $42.2 \pm 19.5 \mu \mathrm{mol} / \mathrm{L}$ before dialysis and $17.7 \pm 6.5 \mu \mathrm{mol} / \mathrm{L}$ after dialysis, showing significant decrease $(P=0.011)$. Free carnitine levels decreased significantly from $27.0 \pm 13.2 \mu \mathrm{mol} / \mathrm{L}$ before dialysis to 11.2 $\pm 25.4 \mu \mathrm{mol} / \mathrm{L}$ after dialysis $(P=0.009)$; acylcarnitine levels decreased significantly from $15.2 \pm 6.2 \mu \mathrm{mol} / \mathrm{L}$ to $5.8 \pm 1.9 \mu \mathrm{mol} / \mathrm{L}(P=0.021)$ (Figure 2). In 5 patients treated with $\mathrm{LC}$, the levels of serum total carnitine, free carnitine, and acylcarnitine before and after administration increased significantly from $42.0 \pm 24.3 \mu \mathrm{mol} / \mathrm{L}$ to $155.0 \pm 114.8 \mu \mathrm{mol} / \mathrm{L}, 26.4 \pm 15.3 \mu \mathrm{mol} / \mathrm{L}$ to $102.9 \pm 80.1 \mu \mathrm{mol} / \mathrm{L}$, and from $16.8 \pm 10.1 \mu \mathrm{mol} / \mathrm{L}$ to $60.8 \pm 34.3$ $\mu \mathrm{mol} / \mathrm{L}$ (Figure 3).

\subsection{Non-Dialysis Patients}

In the non-dialysis patients, no significant differences was observed in patient backgrounds (age, sex, cause, Child-Pugh grade, complication by liver cancer, total carnitine concentration, and with or without BCAAs administration) between the LC group of 12 patients and non-administration group of 7 patients. By Child-Pugh grades, serum total carnitine showed little variation (grade A, $67.4 \pm 20.4 \mu \mathrm{mol} / \mathrm{L}$; grade B, $51.6 \pm 18.8 \mu \mathrm{mol} / \mathrm{L}$; 
Table 2. Cramps, one of the symptoms experienced by patients with hepatic cirrhosis, developed in $67 \%$ (18 of 27 patients) of the patients, consisting of 50\% (4 of 8 patients) of the dialysis patients and $74 \%$ (14 of 19 patients) of the non-dialysis patients (a). The administration of LC caused the cramps to disappear in $92 \%$ (12 of 13 patients) of the patients, while the symptom did not disappear in the absence of LC administration, showing a significant difference between the two groups ( $P$ $=0.0002)(\mathbf{b})$.

(a)

\begin{tabular}{|c|c|c|c|c|c|c|}
\hline \multicolumn{7}{|c|}{ Incidence on muscle cramp } \\
\hline & Total patients $\mathrm{n}=27$ & Hemodialysis & $\mathrm{n}=8$ & Non-hempdialysis & $\mathrm{n}=19$ & $P$ value \\
\hline Muscle cramp (\%) & $18(67)$ & $4(50)$ & & $14(74)$ & & 0.3748 \\
\hline
\end{tabular}

(b)

\begin{tabular}{|c|c|c|c|}
\hline \multicolumn{4}{|c|}{ Improvements on muscle cramp } \\
\hline & L-carnitine $\mathrm{n}=13$ & Non-L-carnitine $\mathrm{n}=4$ & $P$ value \\
\hline Disappearance of muscle cramp (\%) & $12 / 13(92)$ & $0 / 4(-)$ & $0.0002^{*}$ \\
\hline Hemodialysis & 3/3 (100) & $0 / 1(-)$ & 0.2500 \\
\hline Non-hemodialysis & $9 / 10(90)$ & $0 / 3(-)$ & $0.0140^{*}$ \\
\hline
\end{tabular}

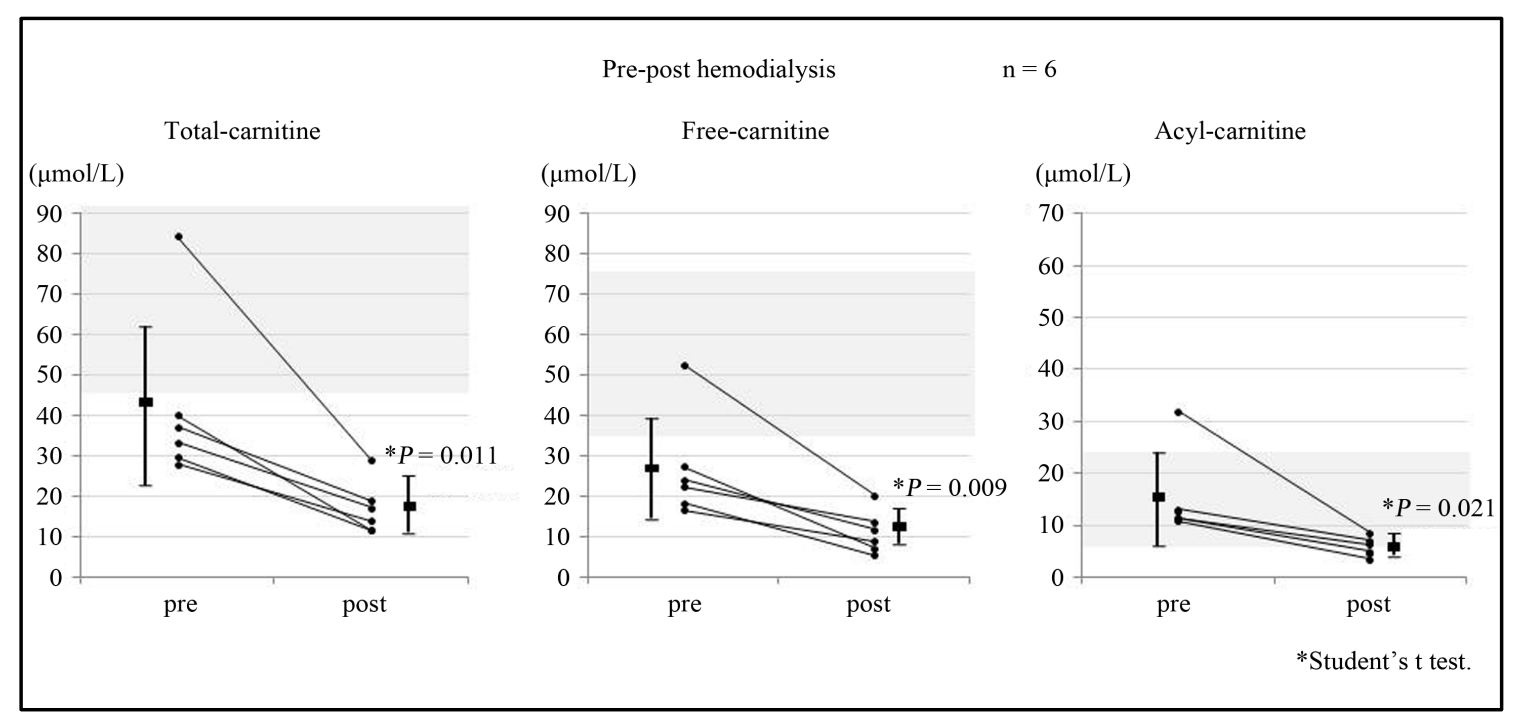

Figure 2. The total carnitine concentration of 6 dialysis patients whose serum carnitine concentrations were measured was a subnormal $42.2 \pm 19.5 \mu \mathrm{mol} / \mathrm{L}$ before dialysis and $17.7 \pm 6.5 \mu \mathrm{mol} / \mathrm{L}$ after dialysis, showing significant decrease $(P=0.011)$. Free carnitine levels decreased significantly from $27.0 \pm 13.2 \mu \mathrm{mol} / \mathrm{L}$ before dialysis to $11.2 \pm$ $25.4 \mu \mathrm{mol} / \mathrm{L}$ after dialysis $(P=0.009)$; acylcarnitine levels decreased significantly from $15.2 \pm 6.2 \mu \mathrm{mol} / \mathrm{L}$ to $5.8 \pm 1.9$ $\mu \mathrm{mol} / \mathrm{L}(P=0.021)$.

grade $\mathrm{C}, 71.6 \pm 28.1 \mu \mathrm{mol} / \mathrm{L}$ ); free carnitine also exhibited little variation (grade $\mathrm{A}, 51.6 \pm 16.8 \mu \mathrm{mol} / \mathrm{L}$; grade $\mathrm{B}$, $56.3 \pm 10.9 \mu \mathrm{mol} / \mathrm{L}$; grade C, $55.0 \pm 18.9 \mu \mathrm{mol} / \mathrm{L}$ ); and acylcarnitine also showed little variation (grade A, 15.8 $\pm 8.9 \mu \mathrm{mol} / \mathrm{L}$; grade B, $18.3 \pm 9.9 \mu \mathrm{mol} / \mathrm{L}$; grade $\mathrm{C}, 16.6 \pm 10.5 \mu \mathrm{mol} / \mathrm{L})$, neither of which showed a significant difference (Figure 4). In 12 patients treated with LC, the serum total carnitine levels before and after administrations increased significantly from $71.7 \pm 22.8 \mu \mathrm{mol} / \mathrm{L}$ to $101.7 \pm 45.5 \mu \mathrm{mol} / \mathrm{L}(P=0.038)$; free carnitine increased significantly from $54.9 \pm 15.4 \mu \mathrm{mol} / \mathrm{L}$ to $84.4 \pm 36.2 \mu \mathrm{mol} / \mathrm{L}(P=0.012)$; and acylcarnitine increased from $16.8 \pm 9.1 \mu \mathrm{mol} / \mathrm{L}$ to $17.3 \pm 9.8 \mu \mathrm{mol} / \mathrm{L}$, showing an upward trend (Figure 5). Since no improvement was observed in 1 LC-treated case (cramps developed several times monthly), the dose of LC was increased, and consequently the symptom was improved 1 month later. 
Front carnitine part drawing pre and post L-carnitine $\quad \mathrm{n}=5$
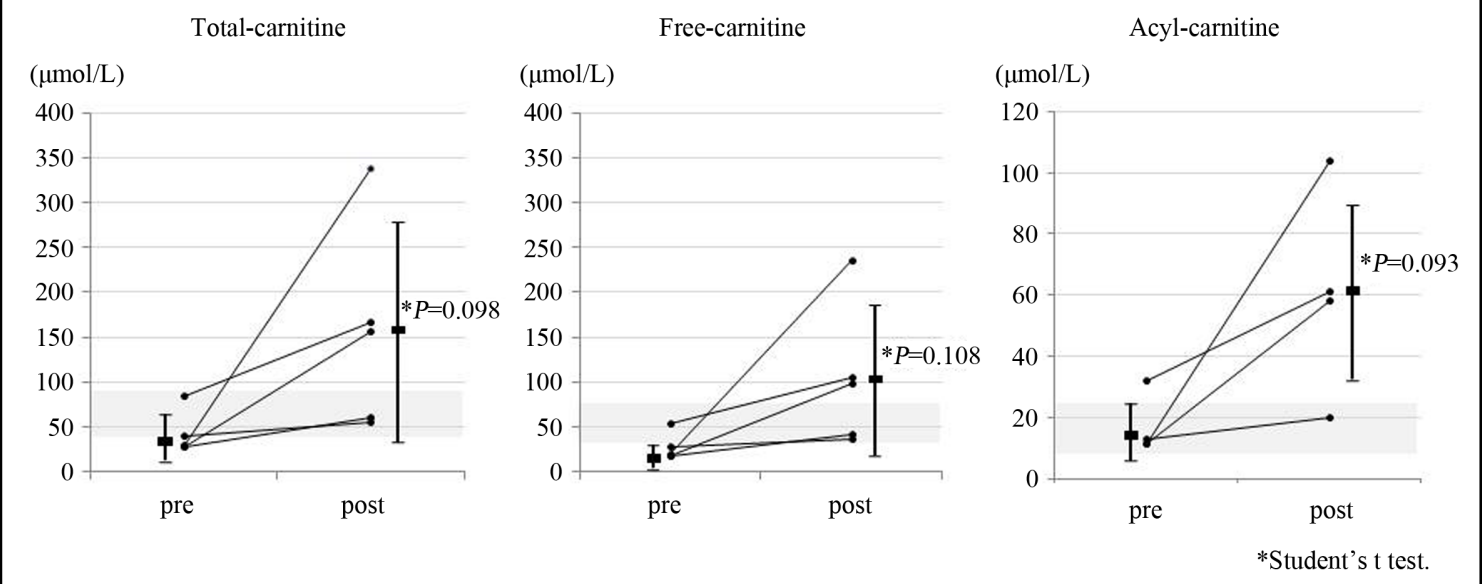

Figure 3. 5 patients treated with LC, the levels of serum total carnitine, free carnitine, and acylcarnitine before and after administration increased significantly from $42.0 \pm 24.3 \mu \mathrm{mol} / \mathrm{L}$ to $155.0 \pm 114.8 \mu \mathrm{mol} / \mathrm{L}, 26.4 \pm 15.3 \mu \mathrm{mol} / \mathrm{L}$ to $102.9 \pm 80.1 \mu \mathrm{mol} / \mathrm{L}$, and from $16.8 \pm 10.1 \mu \mathrm{mol} / \mathrm{L}$ to $60.8 \pm 34.3 \mu \mathrm{mol} / \mathrm{L}$.

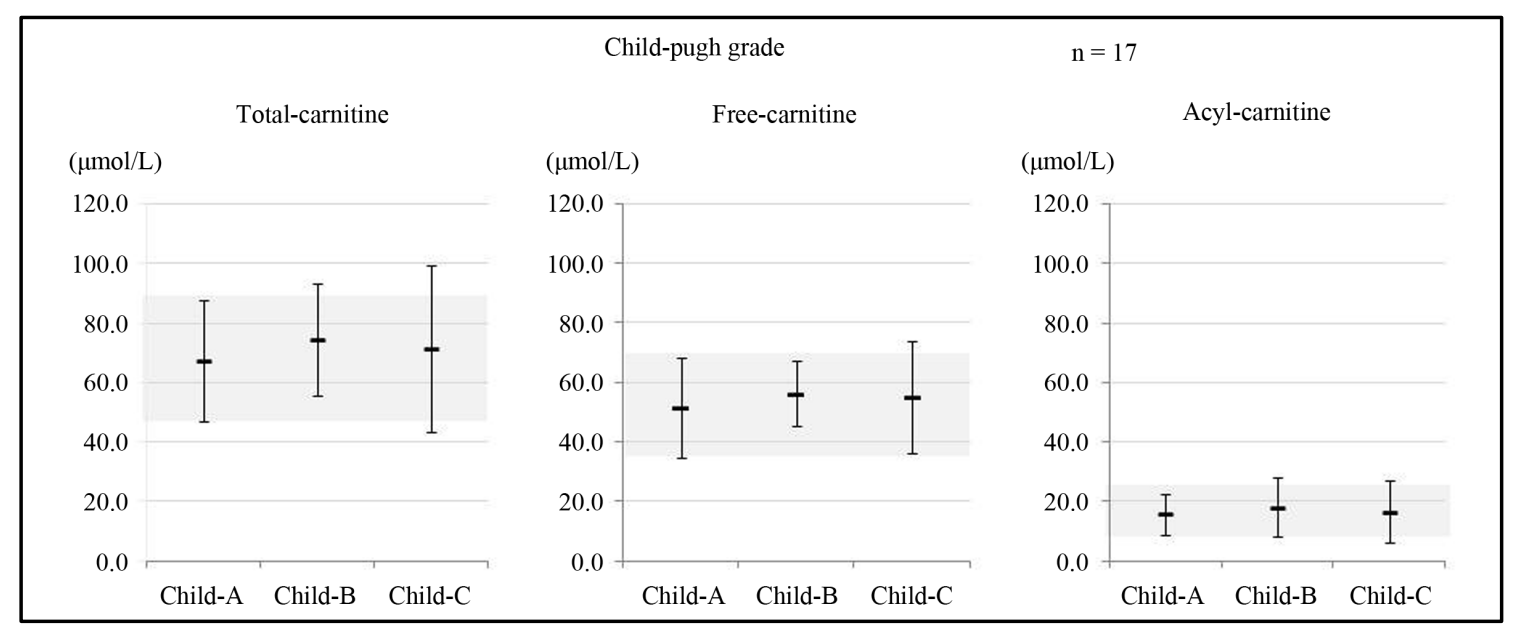

Figure 4. Child-Pugh grades, serum total carnitine showed little variation (grade A, $67.4 \pm 20.4 \mu \mathrm{mol} / \mathrm{L}$; grade B, 51.6 $\pm 18.8 \mu \mathrm{mol} / \mathrm{L}$; grade C, $71.6 \pm 28.1 \mu \mathrm{mol} / \mathrm{L}$ ); free carnitine also exhibited little variation (grade A, $51.6 \pm 16.8$ $\mu \mathrm{mol} / \mathrm{L}$; grade B, $56.3 \pm 10.9 \mu \mathrm{mol} / \mathrm{L}$; grade $\mathrm{C}, 55.0 \pm 18.9 \mu \mathrm{mol} / \mathrm{L}$ ); and acylcarnitine also showed little variation (grade A, $15.8 \pm 8.9 \mu \mathrm{mol} / \mathrm{L}$; grade B, $18.3 \pm 9.9 \mu \mathrm{mol} / \mathrm{L}$; grade C, $16.6 \pm 10.5 \mu \mathrm{mol} / \mathrm{L}$ ), neither of which showed a significant difference.

\section{Discussion}

Takayanagi reported that carnitine was an amino acid derivative with low molecular weight and played an important role in energy metabolism [7]. He presented the following three reasons for this: a) carnitine is essential for transportation of long-chain fatty acids to mitochondria; b) it adjusts the CoA/acyl-CoA ratio in mitochondria. Replacement of CoA with carnitine generates free CoA in the mitochondria; and c) carnitine removes cytotoxic acyl compounds from the cells as carnitine esters, which are excreted in the urine. Carnitine deficiency is classified into primary and secondary carnitine deficiency [8]. Primary carnitine deficiency is also known as congenital carnitine transporter deficiency or systemic carnitine deficiency. Secondary carnitine deficiency includes other inborn errors of metabolism and acquired medical conditions include: a) decrease in biosyntheses (hepatic cirrhosis, chronic kidney diseases, etc.); b) reduction in intake (long-term management of total parenteral nutrition, malnutrition, etc.); and c) reduction of body stores (pregnant and lactating women, very low birthweight infants, etc.) and those caused by medical interventions (dialysis- or drug-induced). 


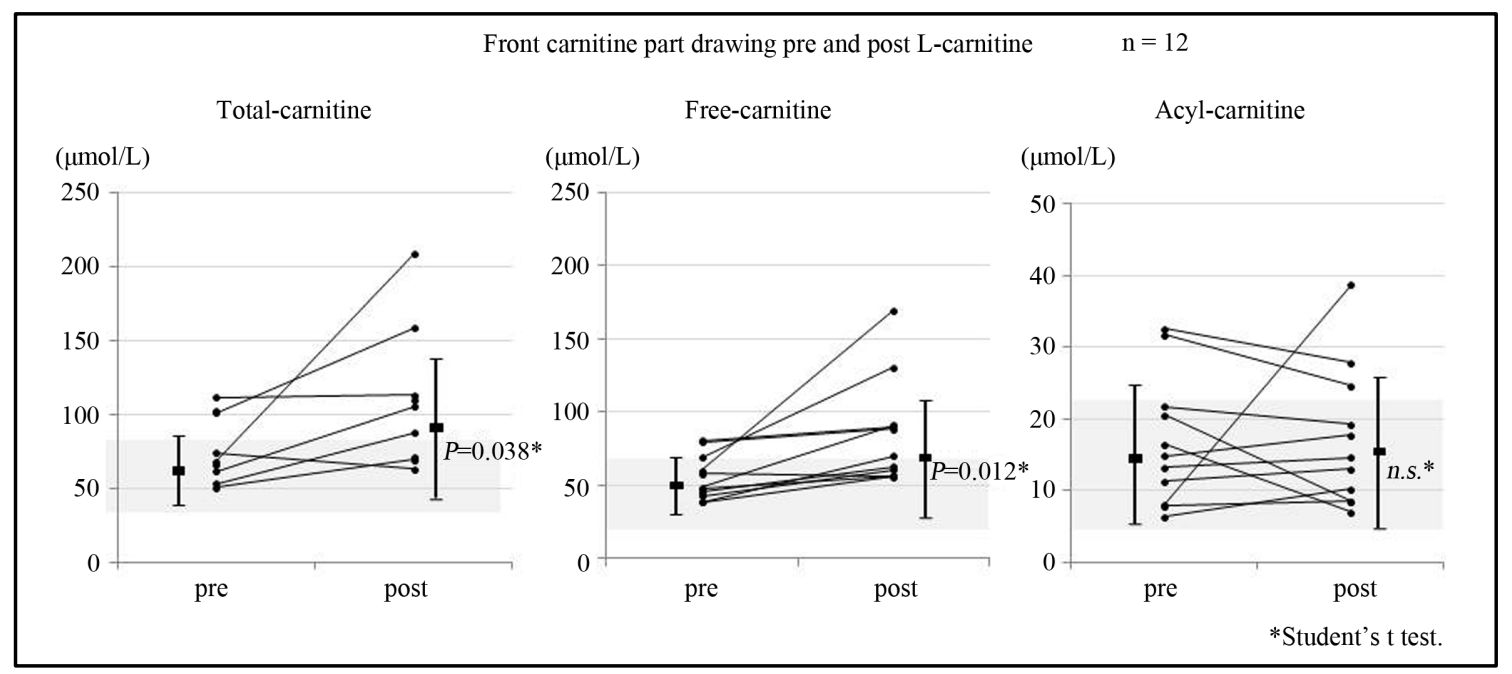

Figure 5. In 12 patients treated with LC, the serum total carnitine levels before and after administrations increased significantly from $71.7 \pm 22.8 \mu \mathrm{mol} / \mathrm{L}$ to $101.7 \pm 45.5 \mu \mathrm{mol} / \mathrm{L}(P=0.038)$; free carnitine increased significantly from $54.9 \pm 15.4 \mu \mathrm{mol} / \mathrm{L}$ to $84.4 \pm 36.2 \mu \mathrm{mol} / \mathrm{L}(P=0.012)$; and acylcarnitine increased from $16.8 \pm 9.1 \mu \mathrm{mol} / \mathrm{L}$ to $17.3 \pm$ $9.8 \mu \mathrm{mol} / \mathrm{L}$, showing an upward trend.

The cases that we examined in this study were likely to have been those of secondary carnitine deficiency. The symptom of cramps in patients with hepatic cirrhosis is occasionally encountered in clinical practice, and switching therapeutic drugs from BCAA formulations or BCAA granules to oral nutrients for liver failure may improve the symptom [9]. Also, it has been reported that the causes for cramps are mechanism of peripheral neuropathy or myogenic, and decrease in blood taurine levels, which suppress abnormal excitation at the neuromuscular junction. Goto et al. discussed that BCAA formulations improved the symptom via decreased levels of free L-tryptophan caused by increased serum albumin levels, followed by facilitated ability to synthesize taurine through correction of amino acid imbalance [10]. We sometimes come across cases in which muscle symptoms occur as a result of carnitine deficiency in dialysis patients as well [11]. In 10 studies by Sakurauchi et al., LC formulation was orally administered to 30 maintenance dialysis patients at a dose of $500 \mathrm{mg}$ for 12 weeks, and the patients' somatic symptoms were assessed. As a result, it was reported that muscle symptoms (including fatigue, muscle spasm, and muscle pain) had improved in two-thirds of the patients [12]. In dialysis patients who develop cramps as a result of carnitine deficiency, it is said that muscle symptoms occur due to increased burden on each cell because of insufficient energy production in the muscle cells compared to healthy individuals by shifting of the energy sources from fatty acids to sugars and proteins, which in turn are caused by decreased blood and muscle carnitine levels. It is considered that LC administration allows the long-chain fatty acids to become sufficiently available again, and the acyl compounds accumulated in the cells to be washed out by carnitine, normalizing the cells, and these factors are involved in improvement of the muscle symptoms [13]. A metaanalysis by Lynch et al. that integrated the findings of 6 studies revealed that the use of LC significantly improved muscle spasms during dialysis in 2 cases [14]. Changes in the muscle fibers in dialysis patients and carnitine deficiency are also being examined; however, no characteristic changes have been noted [15] [16]. Administration of carnitine to these patients, however, increased the long diameters of type 1 muscle fibers. In these reactions, the type 1 muscle fibers contain many mitochondria, whose metabolism is aerobic. Therefore, what obtains benefits from carnitine administration is type 1 muscle fibers; uptake of fatty acids into the mitochondria increases, cell metabolism increases, the long diameters of the muscle fibers increase, and the proportion of atrophic muscle fibers to total muscle fibers decreases [17]. Although muscle biopsies were not carried out in any of the present cases, such mechanism is likely to be responsible for the improvement in the symptom. We need to consider the doses and duration of administration in future investigations. We also need to search for alternative test items in the future because serum carnitine fractionation is currently not covered by insurance.

\section{References}

[1] Malguarnera, M., Vacante, M., Motta, M., et al. (2001) Acetly-L-Carnitine Improves Cognitive Functions in Severe 
Hepatic Encephalopathy: A Randomized and Controlled Clinical Trial. Metabolic Brain Disease, 26, 281-289, http://dx.doi.org/10.1007/s11011-011-9260-z

[2] Malguarnera, M., Gargante, M.P., Cristaldi, E., et al. (2008) Acetyl-L-Carnitine Treatment in Minimal Hepatic Encephalopathy. Digestive Diseases and Sciences, 53, 3018-3025. http://dx.doi.org/10.1007/s10620-008-0238-6

[3] Malguarnera, M., Bella, R., Vacante, M., et al. (2011) Acetly-L-Carnitine Reduces Depression and Improves Quality of Life in Patients with Minimal Hepatic Encephalopathy. Scandinavian Journal of Gastroenterology, 46, 750-759. http://dx.doi.org/10.3109/00365521.2011.565067

[4] Moorthy, A.V., Rosenblum, M., Rajaram, R., et al. (1983) A Comparison of Plasma and Muscle Carnitine Levels in Patients on Peritoneal or Hemodialysis for Chronic Renal Falure. American Journal of Nephrology, 3, 205-208. http://dx.doi.org/10.1159/000166711

[5] Hiatt, W.R., Koziol, B.J., Shapiro, J.L., et al. (1992) Carnitine Metabolism during Exercise in Patients on Chronic Hemodialysis. Kidney International, 41, 1613 -1619. http://dx.doi.org/10.1038/ki.1992.233

[6] Ahmad, S., Robartson, H.T., Golper, T.A., et al. (1990) Multicenter Trial of L-Carnitine in Maintenance Hemodialysis Patients 2. Clinical and Biochemical Effects. Kidney International, 38, 912-918. http://dx.doi.org/10.1038/ki.1990.290

[7] Takayanagi, M. (2009) Abnormality. Carnitine Metabolism Child Internal Medicine, 41, The Special Number 387-389.

[8] Pons, R. and De Vivo, D.C. (1995) Primary and Secondary Carnitine Deficiency Syndrome. Journal of Child Neurology, 10, S8-S24.

[9] Kaneko, Y. and Tsuchiyama, H. (2012) Examination of the Usefulness of the Oral Nutrition Agent for Hepatic Insufficiency to Liver Cirrhosis. Frontiers in Gastroenterology, 17, 94-101.

[10] Goto, N., Iida, K. and Hagisawa, Y. (2001) Usefulness of the Branched-Chain-Amino-Acid Tablet to the Leg Cramps Accompanying Liver Cirrhosis. Liver, 42, 590-599.

[11] Casciani, C.U. and Caruso, U. (1982) Beneficial Effects of L-Carnirine in Post-Dialysis Sundrome. Current Therapeutic Research, 132, 116-127.

[12] Sakurauchi, Y., Matsumoto, Y., Shinzato, T., et al. (1998) Effects of L-Carnitine Supplementation on Muscular Symotpms in Hemodaialyzed Patients. American Journal of Kidney Diseases, 32, 258-264. http://dx.doi.org/10.1053/ajkd.1998.v32.pm9708610

[13] Borum, P.R. and Taggart, E.M. (1986) Carnitine Nutriture of Dialysis Parients. Journal of the American Dietetic Association, 86, 644-647.

[14] Lynch, K.E., Feldman, H.I., Berlin, J.A., et al. (2008) Effects of L-Carnitine on Dialysis-Related Hypotension and Muscle Cramps: A Meta-Analysis. American Journal of Kidney Diseases, 52, 962-971. http://dx.doi.org/10.1053/j.ajkd.2008.05.031

[15] Siami, G., Clinton, M.E., Mrak, R., et al. (1991) Evaluation of the Effect of Intravenous L-Carnitine Therapy on Function, Structure and Fatty Acid Metabolism of Skeletal Muscle in Patients Receiving Chronic Hemodialysis. Nephron, 57, 306-313. http://dx.doi.org/10.1159/000186280

[16] Ginvenali, P., Fenocchio, D., Montanari, G., et al. (1994) Selective Trophic Effect of L-Carnitine Type 1 and 2 Skeletal Muscle Fibers. Kidney International, 46, 1616-1619. http://dx.doi.org/10.1038/ki.1994.460

[17] Takahashi, T., Hashimoto, Y. and Doi, T. (2000) No 220 Carnitine and Muscles. Clinical Dialysis, 16, 201-206. 